\title{
Preclinical Evaluation of Anxiolytic Activity of Adhatoda Vasica Leaf Extract in Swiss Albino Mice
}

\author{
Prabhakar Adake, Kumar Gourav, Mahalaxmi S Petimani* \\ Yenepoya Medical College, Yenepoya (Deemed to be University), India \\ Received February 8, 2020; Revised April 22, 2020; Accepted April 27, 2020
}

Copyright $\bigcirc 2020$ by authors, all rights reserved. Authors agree that this article remains permanently open access under the terms of the Creative Commons Attribution License 4.0 International License

\begin{abstract}
Objectives: To evaluate the possible anxiolytic activity of methanolic extract of Adhatoda vasica leaves (MEAVL) in Swiss albino mice. Methods: A total of $60(n=60)$ mice were used. They were divided into ten groups of six mice each. The dose of 200, 400 and $600 \mathrm{mg} / \mathrm{kg}$ MEAVL were chosen after acute toxicity study. First 5 groups were evaluated by Elevated Plus Maze (EPM) and rest 5 group were evaluated by Light and Dark Arena (LDA) model. First group of mice (control) received $0.05 \mathrm{ml} / 10 \mathrm{~g}$ of Normal Saline, second group (standard) received $1.0 \mathrm{mg} / \mathrm{kg}$ Diazepam, third, fourth and fifth group received 200, 400 and $600 \mathrm{mg} / \mathrm{kg}$ of MEAVL respectively. Anti-anxiety effect was evaluated 60 min after the oral drug administration. Results: All the results were expressed in mean \pm SD. One way ANOVA followed by Tukey- Kramer multiple comparison tests were used to compare between groups. In EPM model, the numbers of entries in open arm were $3.50 \pm 1.64,13.17 \pm 7.44,7.50 \pm 4.63$, $3.67 \pm 1.86$ and $4.67 \pm 2.94$ respectively noted for $1^{\text {st }}$ to $5^{\text {th }}$ groups respectively for Normal Saline, Diazepam, 200, 400 and $600 \mathrm{mg} / \mathrm{kg}$ of MEAVL. Similarly in LDA model, the numbers of entries in dark arena were $12.17 \pm 1.47$, $13.17 \pm 2.92, \quad 12.33 \pm 3.01,7.17 \pm 1.94$ and $10.50 \pm 3.08$ respectively noted for $6^{\text {th }}$ to $10^{\text {th }}$ group. This result clearly showed that MEAVL-400mg/KG has antianxiety property when compared to diazepam as evidenced by increase in the number of entries in dark arena in LDA model with $\mathrm{p}<0.05$. In EPM, MEAVL showed increase in the time spent in open arm and decrease in the time spent in closed arm, as well as increase in the number of entries in the open arm but it was not statistically significant $(p>0.05)$. Conclusion: The current study has demonstrated an antianxiety effect of MEAVL in a dose of $400 \mathrm{mg} / \mathrm{kg}$ in LDA model. However, the study plant must be further evaluated to confirm the molecular basis of the antianxiety property so that it can be helpful for the society in the near future because of its antianxiety property.
\end{abstract}

Keywords Adhatoda vasica, Elevated Plus Maze,
Light and Dark Arena

\section{Introduction}

Anxiety disorders, the most common psychiatric illnesses in the general population. Around 15-20\% patients in general practice present with anxiety disorders. It is characterized by excessive rumination, worrying, uneasiness, apprehension and fear about future uncertainties either based on real or imagined events, which may affect both physical and psychological health. Numerous studies have shown that patients with anxiety disorders over-estimate the dangerousness of various stimuli.

Current psychiatric diagnostic criteria recognize a wide variety of anxiety disorders. Recent surveys have found that as many as $18 \%$ of Americans, $20.7 \%$ of Indians and $14 \%$ of Europeans may be affected by one or more of them. [1]

The DSM-IV (American Psychiatric Association) includes the following major categories of anxiety disorders: Panic disorder (with or without agoraphobia), agoraphobia without panic, social phobia (social anxiety disorder), specific phobia, generalized anxiety disorder (GAD), acute stress disorder, posttraumatic stress disorder, obsessive compulsive disorder, and anxiety disorder not otherwise specified. [2]

Low levels of GABA, a inhibitory neurotransmitter in the central nervous system, contribute to anxiety. A number of anxiolytics achieve their effect by modulating the GABA receptors. [3] Benzodiazepines are most commonly used, safe and effective drug in the short term management of anxiety. [4] Long-term use of benzodiazepines has adverse psychological and physical effects. And they are also associated with tolerance, physical dependence and withdrawal syndrome on sudden 
discontinuation. [5] Hence need for newer, better-tolerated and more efficacious treatments remains high.

Oxidative stress mechanisms underlying anxiety disorder has been in existence since long, with the earlier suggestion that NO and peroxy nitrite might play a major role in setting up a vicious etiological cycle involving free radicals and inflammatory cytokines in post-traumatic stress disorder. [6]

Association of vitamin $\mathrm{E}$ depletion and increased oxidative stress markers, anxiety behaviors in phospholipid transfer protein (PLTP) knock-out mice has further enhanced oxidative role in pathogenesis of anxiety. Even clinical studies have reported elevated lipid peroxidation products and antioxidant changes in obsessive-compulsive disorder, panic disorder and social phobia. [7, 8] And following 8 weeks of treatment with citalopram for social phobia, found a reversal of these disturbances. [9]

Thus anti-oxidants could have anxiolytic potential by preventing oxidative pathway. Green tea polyphenol $(-)$ epigallocatechin gallate (EGCG), and chlorogenic acid, a dietary polyphenol, showed anxiolytic effects on mice model with a dose-dependent relationship due to their potent antioxidant property. [10]

Adhatoda vasica, also known as malabar nut tree is part of the Acanthaceae plant family. It is a small evergreen, sub-herbacious bush which grows commonly in open plains, especially in the lower Himalayas (up to 1300 meters above sea level), India, Sri Lanka, Burma and Malaysia, widely used in Siddha Medicine, Ayurvedic, homeopathy and Unani systems of medicine. [11]

The leaves of Adhatoda vasica contain phytochemicals such as alkaloids, tannins, saponins, phenolics and flavonoids. The most important is vasicine, a quinazoline alkaloid. [12]

The plant is recommended for a variety of ailements such as bronchitis, asthma, fever, jaundice etc. The leaves $\&$ roots are efficacious in coughs, arthritis, diarrhoea and dysentery and have the best chemostatic quality. Leaves are anti-inflammatory, analgesic effective in skin disorders, cardiotonic. This is one of the most potent anti-tuberculosis drugs. Vasicine is also reported for its anthelmintic and weak hypertensive activity. [13]

Methanol extract of Adhatoda vasica showed maximum photochemical, antioxidant enzymes and antimicrobial assay as compared to aqueous extract of Adhatoda vasica. [14]

So the present study carried out to elucidate the possible anxiolytic activity in Swiss albino mice.

\section{Objective}

- To evaluate the possible anxiolytic activity of Adhatoda vasica leaf extract in Swiss albino mice.

\section{Materials and Methods}

Animals: Institutional Ethical clearance was obtained before conducting the study. A total of $60(n=60)$ male Swiss albino mice weighing 25-35 g. were used in this study. They were divided into ten groups of six mice in each. Anxiolytic activity of MEAV was evaluated by using two models -Elevated plus maze (EPM) and light and dark arena (LDA). The experiment was conducted in Ethanopharmacology laboratory of the Department of Pharmacology, Yenepoya Medical College, Yenepoya University, between 8:00 A.M. to 2:00 P.M. The food and water were removed during study period. Each mouse was weighed and appropriate dose of drug was given per orally (p.o) depending on the group. The experiment was conducted sixty minutes after the oral administration of the drug.

First five groups were evaluated for EPM and remaining five groups by LDA model of anxiety. The study was conducted in accordance with standard CPCSEA guidelines.

Collection of plant material: Adhatoda vasica leaf powder was be purchased from the Global herbal supplies, India. Powder was subjected to solvent extraction using methanol in a soxhlet apparatus. After exhaustive extraction, the methanolic extract was dried at low temperature under reduced pressure in a rotary evaporator to obtain greenish-black colored residue which was used for anxiolytic studies.

Drugs: The standard antianxiety drug tablet Diazepam was purchased from our institutional pharmacy.

\section{Inclusion Criteria}

- $\quad$ Male Swiss albino mice weighing between 25-35g.

- $\quad$ Age 3-4 months.

- Healthy with normal behavior and activity.

\section{Exclusion Criteria}

- $\quad$ Mice $<25 g$ and $>35$ and age $<3$ months and $>4$ months.

- $\quad$ Female mice were excluded

- Animals previously used in other experiments.

A total of 60 animals $(n=60)$ was used. They were divided into ten groups of six animals each.

Acute oral toxicity test: Acute oral toxicity was carried out in male Swiss albino mice according to Organization of Economic Co-operation and Development (OECD) guidelines, ANNEX-423. $\left[{ }^{15}\right.$ Mice were administered methanolic extract of Adhatoda vasica leaves (MEAVL) in a dose of 5,50, 300 and $2000 \mathrm{mg} / \mathrm{kg}$ per orally to find out safe dose range in animals. Animals were observed for 48 hours from the time of drug administration. Mice were looked for general behavior and mortality. 
Elevated plus maze: It is a novel test for the evaluation of anxiolytic drug effects in rodents. The wooden plus maze consists of two open arms (length $16 \mathrm{~cm} \mathrm{X}$ breadth $5 \mathrm{~cm}$ ) and two closed arms of the same size (height 12 $\mathrm{cm})$. The arms of the same type are opposite to each other, with a central square of $5 \mathrm{~cm}$. The maze was elevated to a height of $25 \mathrm{~cm}$ above the floor. The apparatus consists of an open top wooden box. The mouse is placed at the centre of the elevated maze with their head facing towards open arm during $5 \mathrm{~min}$ test period. The preference of the mouse for first entry, the number of entries into the open and closed arms reflects the relative safety of closed arms as compared with the relative fearfulness of open arms. Mouse being rodent feel safe in dark, hence normal rodents prefer dark arm first. Anxiolytics would be expected to increase the proportion of entries into and time spent in open arms. [16]

Light and dark arena: The apparatus consisted a rectangular box $(45 \times 27 \times 27 \mathrm{~cm})$, partitioned in to two compartments connected by a $7.5 \times 7.5 \mathrm{~cm}$ opening in the wall between compartments. The mice are placed in the center of the light compartment and were observed for 5 min for the time spent in light compartment. [17]

\section{Results}

All the results were expressed in mean \pm SD. One way ANOVA followed by Tukey- Kramer multiple comparison tests were used to compare between groups

\section{Acute Toxicity Study}

Acute oral toxicity test was carried out in male Swiss albino mice according to Organization of Economic
Co-operation and Development (OECD) guidelines, ANNEX- 423.Mice were administered MEAV in a dose of 5, 50, 300 and $2000 \mathrm{mg} / \mathrm{kg}$ per orally to find out safe dose range in animals. Animals were observed for 48 hours from the time of drug administration and looked for general behavior and mortality. There was no morbidity or mortality. So the dose range of 200, 400, and $600 \mathrm{mg} / \mathrm{kg}$ MEAVL were selected for the present study.

\section{Elevated Plus Maze Test}

In EPM model, the numbers of entries in open arm were $3.50 \pm 1.64, \quad 13.17 \pm 7.44, \quad 7.50 \pm 4.63, \quad 3.67 \pm 1.86$ and $4.67 \pm 2.94$ respectively noted for $1^{\text {st }}$ to $5^{\text {th }}$ groups respectively for Normal Saline, Diazepam, 200, 400 and $600 \mathrm{mg} / \mathrm{kg}$ of MEAVL. Mice treated with Diazepam showed increase in the time spent in open arm and decrease in the time spent in closed arm, as well as increase in the number of entries in the open arm (table 1). MEAVL treated mice showed increase in the time spent in open arm and decrease in the time spent in closed arm, as well as increase in the number of entries in the open arm and decrease in the number of entries in the closed arm when compared to control group but it was not statistically significant (table 1).

\section{Light and Dark Arena Test}

Similarly, mice treated with Diazepam showed increase in the time spent in light arena and decrease in the time spent in dark arena (table 2). MEAVL 400mg treated mice has shown increase in the number of entries in light arena and decreased in the number of entries in the dark arena as compared to control and standard drug Diazepam with $\mathrm{p}$ value $<0.05$.

Table 1. Effect of MEAVLon mice behavior in EPM model

\begin{tabular}{|c|c|c|c|c|}
\hline Group & $\begin{array}{c}\text { No of Entry into } \\
\text { open arm }\end{array}$ & $\begin{array}{c}\text { No of Entry into } \\
\text { closed arm }\end{array}$ & Time spent in open arm & Time spent in closed arm \\
\hline $\begin{array}{c}\text { Group I: } \\
\text { NS 10 ml/kg }\end{array}$ & $3.50 \pm 1.64$ & $9.50 \pm 3.61$ & $64.50 \pm 25.80$ & $238.83 \pm 20.41$ \\
\hline $\begin{array}{c}\text { Group II: } \\
\text { Diazepam 1 mg/kg }\end{array}$ & $13.17 \pm 7.44^{*}$ & $16.33 \pm 5.64 *$ & $128.33 \pm 47.59 *$ & $171.67 \pm 47.59 *$ \\
\hline $\begin{array}{c}\text { Group III: } \\
\text { MEAVL200mg/kg }\end{array}$ & $7.50 \pm 4.63$ & $13.67 \pm 4.80$ & $108.50 \pm 34.25$ & $191.50 \pm 34.25$ \\
\hline $\begin{array}{c}\text { Group IV: } \\
\text { MEAVL400mg/kg }\end{array}$ & $3.67 \pm 1.86$ & $10.33 \pm 4.96$ & $90.50 \pm 23.62$ & $209.50 \pm 23.62$ \\
\hline $\begin{array}{c}\text { Group V: } \\
\text { MEAVL600mg/kg }\end{array}$ & $4.67 \pm 2.94$ & $7.67 \pm 2.80$ & $109.67 \pm 37.50$ & $190.33 \pm 37.50$ \\
\hline
\end{tabular}

MEAVL=Methanolic Extract ofAdhatoda vasica leaves; $\mathrm{N}=6$; Mean $\pm \mathrm{SD},{ }^{*} \mathrm{p}<0.05$ on comparing G II with GI ; 
Table 2. Effect of MEAVL on mice behavior in LDA model

\begin{tabular}{|c|c|c|c|c|}
\hline Group & $\begin{array}{c}\text { No of Entry into } \\
\text { light box }\end{array}$ & $\begin{array}{c}\text { No of Entry into } \\
\text { dark box }\end{array}$ & Time spent in light box & Time spent in dark box \\
\hline $\begin{array}{c}\text { Group VI: } \\
\text { NS 10 ml/kg }\end{array}$ & $11.67 \pm 1.36$ & $12.17 \pm 1.47$ & $106.83 \pm 18.21$ & $193.17 \pm 18.21$ \\
\hline $\begin{array}{c}\text { Group VII: } \\
\text { Diazepam 1 mg/kg }\end{array}$ & $13.17 \pm 2.48$ & $13.17 \pm 2.92$ & $163.50 \pm 41.65$ & $136.50 \pm 41.65$ \\
\hline $\begin{array}{c}\text { Group VIII: } \\
\text { MEAVL 200 mg/kg }\end{array}$ & $12.00 \pm 3.72$ & $12.33 \pm 3.01$ & $131.67 \pm 24.76$ & $168.33 \pm 24.76$ \\
\hline $\begin{array}{c}\text { Group IX: } \\
\text { MEAVL 400 mg/kg }\end{array}$ & $7.00 \pm 2.44^{*}$ & $7.17 \pm 1.94 *$ & $75.33 \pm 27.55$ & $224.67 \pm 27.55$ \\
\hline $\begin{array}{c}\text { Group X: } \\
\text { MEAVL 600 mg/kg }\end{array}$ & $11.17 \pm 2.63$ & $10.50 \pm 3.08$ & $107.67 \pm 26.51$ & $192.33 \pm 26.52$ \\
\hline
\end{tabular}

MEAVL=Methanolic Extract ofAdhatoda vasica leaves;N=6; Mean $\pm \mathrm{SD},{ }^{*} \mathrm{p}<0.05$ on comparing G IX with GI \& GII

\section{Discussion}

Everyone feels anxiety time to time, be it facing an exam or interview or perceiving any danger. However, such anxiety is generally occasional, mild and brief. But the anxiety felt by the person with an anxiety disorder occurs frequently, is more intense, and lasts longer. Unfortunately, anxiety disorders are common. [18] Due to the number of side effects and habit forming nature of the current anti-anxiety drugs any new drugs are needed which are free from side effects.

Leaves of Adhatoda vasica was chosen in this study because it contains phytochemicals such as alkaloids, tannins, saponins, phenolics and flavonoids which are antioxidants in nature and these anti-oxidants could have anxiolytic potential by preventing oxidative pathway.Flavonoids, Glycosides, Tannins are responsible for the anti-anxiety activity. [19] For the evaluation of anxiety elevated plus-maze (EPM) and light dark arena (LDA) models were selected. The EPM is the gold standard to assess approach-avoidance behavior in rodents. [20]

Previous studies on Adhatoda vasica have shown it to be a potent antitussive agent. It has no abuse potential whereas codeine is narcotic and hence has high-abuse potential. [21] Crude extract of the leaf of Adhatoda vasica have shown to have anti-bacterial property. [22] The methanolic, chloroform and Diethyl ether extract ointment (10\% w/w) of Adhatoda vasica has significant wound healing activity. [23] Adhatoda vasica leaf powder has also shown considerable degree of antiulcer activity in experimental rats when compared with a control. Aqueous extracts of $A$. vasica leaves showed significant hepatoprotective activity in rats. The antianxiety anxiety activity in present study can be due to the antioxidant property of phytochemicals such as alkaloids, tannins, saponins, phenolics and flavonoids. The study plant must be further evaluated to confirm the molecular basis of the antianxiety property so that it can be helpful for the society in the near future because of its antianxiety property.

\section{Conclusions}

Current study has demonstrated an antianxiety like effect of methanolic extract of Adhatoda vasica leaves in a dose of $400 \mathrm{mg} / \mathrm{kg}$.

\section{REFERENCES}

[1] Kessler RC, Chiu WT, Demler O, Merikangas KR, Walters EE. "Prevalence, severity, and comorbidity of 12-month DSM-IV disorders in the National Comorbidity Survey Replication". Arch. Gen. Psychiatry 2005; 62 (6): 617-627.

[2] Diagnostic and statistical manual for the assessment of mental disorders. 4th ed. Washington, DC: American Psychiatric Association; 1994. American Psychiatric Association.

[3] Lydiard RB. The role of GABA in anxiety disorders. J Clin Psychiatry 2003; 64 (3): 21-27.

[4] Lader M, Tylee A, Donoghue J. Withdrawing benzodiazepines in primary care. CNS Drugs2009;23 (1): 19-34.

[5] Pall ML, Satterlee JD. Elevated nitric oxide/peroxynitrite mechanism for the common etiology of multiple chemical sensitivity, chronic fatigue syndrome, and posttraumatic stress disorder. Annals of the New York Academy of Sciences 2001; 933, 323-329.

[6] Desrumaux C, Risold PY, Schroeder H, Deckert V, Masson D, Athias A, Laplanche H, Le Guern N, Blache D,Jiang $\mathrm{XC}$, et al. Phospholipid transfer protein (PLTP) deficiency reduces brain vitamin $\mathrm{E}$ content and increases anxiety in mice. FASEB Journal 2005; 19, 296-297.

[7] Ersan S, Bakir S, Erdal Ersan E, Dogan O. Examination of free radical metabolism and antioxidant defence system elements in patients with obsessive-compulsive disorder. Progress in Neuropsychopharmacology and Biological Psychiatry 2006; 30, 1039-1042.

[8] Vignes M, Maurice T, Lante F, Nedjar M, Thethi K, Guiramand J, Recasens M. Anxiolytic properties of green tea polyphenol (x)-epigallocatechin gallate (EGCG). Brain Research 2006; 1110: 102-115.

[9] Aslam, Mohd; Rais, Sumbul; Alam, Masood; Pugazhendi, Arulazhagan. "Adsorption of Hg(II) from Aqueous Solution Using Adulsa (Justicia adhatoda) Leaves Powder: Kinetic and Equilibrium Studies". Journal of Chemistry. 2013: 111 . 
[10] Kumar, M., Kumar, A., Dandapat, S. and Sinha, M. P. Phytochemical screening and antioxidant potency of Adhatoda vasica and Vitex negundo, The Bioscan 2013; 8(2): 727-730.

[11] Josephin Sheeba and Selva Mohan. Antimicrobial activity of Adhatoda vasica against clinical pathogens. Asian Journal of Plant Science and Research, 2012; 2 (2):83-88.

[12] Inderjit Kaur1, P.K. Chauhan, Munish Jaryal, Shubham Saxena and Kanishak. Antioxidant and antimicrobial activity of leaf extract of Adhatoda Vasica against the bacteria isolated from the sputum samples of asthmatic patients. Int. J. Drug Res. Tech. 2012; 2 (3): 273-278.

[13] Abrar Hussain Mir, Manjusha Sexena and Mohd Yousuf Malla.An acute oral toxicity study of methanolic extract from Tridex procumbens in Sprague Dawley's Rats as per OECD guidelines 423. Asian Journal of Plant Science and Research 2013; 3(1): 16-20.

[14] Kulkarni SK. Delhi: Vallabh Prakashan; 1999. Handbook of Experimental Pharmacology; pp. 135-37.

[15] Crawley J, Goodwin FK. Preliminary report of a simple animal behavior model for the anxiolytic effects of benzodiazepines. Pharmacol Biochem Behav. 1980; 13: 167-70.

[16] Rector NA, Bourdeau D, Kitchen K and Massiah LJ. Anxiety disorders an information guide. Canada: CAMH Publication 2005; 1-14.

[17] Kanimozhi C. Preclinical Validation of Anti-Anxiety, Anti-Depressant and Anti-Convulsant activity of classical Siddha drug Kandathirika Chooranam in Animal Model (Doctoral dissertation, Government Siddha Medical College, Chennai).

[18] Biedermann SV, Biedermann DG, Wenzlaff F, Kurjak T, Nouri S, Auer MK, Wiedemann K, Briken P, Haaker J, Lonsdorf TB, Fuss J. An elevated plus-maze in mixed reality for studying human anxiety-related behavior. BMC biology. 2017; 15(1): 125.

[19] Dhuley JN. Antitussive effect of Adhatoda vasica extract on mechanical or chemical stimulation-induced coughing in animals. Journal of Ethnopharmacology. 1999; 67(3): 361-5.

[20] Karthikeyan A, Shanthi V, Nagasathaya A. Preliminary phytochemical and antibacterial screening of crude extract of the leaf of Adhatoda vasica. L. International Journal of Green Pharmacy. 2009; 3(1).

[21] Vinothapooshan G, Sundar K. Wound healing effect of various extracts of Adhatoda vasica. Int J Pharm Bio Sci. 2010; 1(4): 530-6.

[22] Shrivastava N, Srivastava A, Banerjee A, Nivsarkar M. Anti-ulcer activity of Adhatoda vasica Nees. Journal of herbal pharmacotherapy. 2006; 6(2): 43-9.

[23] Bhattacharyya D, Pandit S, Jana U, Sen S, Sur TK. Hepatoprotective activity of Adhatoda vasica aqueous leaf extract on D-galactosamine-induced liver damage in rats. Fitoterapia. 2005; 76(2): 223-5. 